\title{
Medisch studenten en hun opvattingen over professionele autonomie
}

J.A. Dekker, W.P.J. van Oosterhout, M.M.C. Lambregts, namens het KNMG Studentenplatform*

\section{Samenvatting}

Inleiding: De geneeskunde is zo'n specifieke professie dat de wetgever het aan artsen zelf overlaat om vast te stellen hoe de beroepsgroep behoort te handelen. Dit wordt ook wel professionele autonomie genoemd.

Methode: In opdracht van het KNMG Studentenplatform is een enquête uitgevoerd onder ruim 6000 studentleden van de KNMG. Onderzocht werd wat studenten geneeskunde onder professionele autonomie verstaan, welk belang ze daaraan hechten en hoe ze aankijken tegen protocollering.

Resultaten: Uit dit onderzoek blijkt dat 59\% van de respondenten autonomie een absolute voorwaarde vindt om het werk als arts te kunnen uitvoeren. Alleen de arts kan en mag bepalen wat de inhoud van goede zorg is, meent $38 \%$. Volgens $23 \%$ vormen protocollen een inperking van de professionele autonomie.

Discussie en conclusie: Vanwege de bijzondere verantwoordelijkheid van de arts (professionele autonomie), de kennis die daarvoor nodig is en de behoefte van studenten aan juridische, administratieve en gezondheidsrechtelijke aspecten, acht het KNMG Studentenplatform het wenselijk om het vak gezondheidsrecht verplicht te stellen in het curriculum. Dit stelt studenten, en de artsen die zij later zullen worden, in staat zich een meer realistisch beeld te vormen van professionele autonomie. (Dekker JA, Oosterhout WPJ van, Lambregts MMC. Medisch studenten en hun opvattingen over professionele autonomie. Tijdschrift voor Medisch Onderwijs 2008;27(4):166-170.)

\section{Inleiding}

In de basisopleiding geneeskunde is van oudsher veel aandacht voor basisvakken als anatomie, fysiologie en ziekteleer. Het artsenberoep vraagt echter om veel meer dan alleen medische kennis. Artsen vormen een beroepsgroep met aanzien en maatschappelijke verantwoordelijkheid. De geneeskunde was zo'n specifieke professie dat de wetgever het aan de artsen zelf overliet om vast te stellen hoe de beroepsgroep behoorde te handelen: dit wordt ook wel professionele autonomie genoemd. De gezondheidszorg is echter aan veranderingen onderhevig. De invoering van marktwerking en de opkomst van het management-denken in de gezondheidszorg leiden ertoe dat artsen meer en meer verantwoording moeten afleggen. ${ }^{1}$ Doordat er meer dan vroeger wordt gewerkt in teamverband en er in de ziekenhuizen taakherschikking plaatsvindt, veranderen de verantwoordelijkheden van de arts. Deze veranderingen hebben gevolgen

\footnotetext{
* Het KNMG Studentenplatform is een landelijke en onafhankelijke belangenbehartiger van studenten geneeskunde. Het platform houdt zich bezig met onderwerpen die studenten geneeskunde in heel Nederland aangaan en die de lokale situatie op de medische faculteiten overstijgt. De standpunten van het KNMG Studentenplatform worden zoveel mogelijk gebaseerd op representatief (opinie)onderzoek (www.knmgstudentenplatform.nl)
} 
Medisch studenten en professionele autonomie $\mid$ J.A. Dekker et al.

voor de autonomie van de arts van straks en zijn dus relevant voor iedere student geneeskunde. Studenten geneeskunde zouden daarom in hun basisopleiding naast medische kennis ook voldoende kennis over de juridische en administratieve en maatschappelijke aspecten van hun toekomstige beroep moeten opdoen. De consensus van de beroepsgroep, die haar waarde ontleent aan de professionele autonomie, is vastgelegd in standaarden, richtlijnen en protocollen.

Het KNMG Studentenplatform deed onderzoek naar wat studenten geneeskunde onder professionele autonomie verstaan, welk belang ze daaraan hechten en hoe ze aankijken tegen protocollering. Bij het gebruik van de term 'professionele autonomie' werd de definitie van de KNMG gehanteerd: "De vrijheid van oordeelsvorming van de arts om, gegeven de wettelijke kaders en de professionele standaarden, zonder inmenging van derden, in de individuele arts-patiëntrelatie te komen tot diagnosestelling en advisering over behandeling en/of het verrichten van diagnostische en therapeutische interventies, waarbij inbegrepen het onderzoeken, het geven van raad met als doel de bescherming en/of verbetering van de gezondheidstoestand van de patiënt." 2

\section{Methode}

Om er achter te komen hoe de artsen van de toekomst denken over autonomie werd gebruik gemaakt van het Studentenpanel. Deze jaarlijkse digitale enquête van het KNMG Studentenplatform werd in februari 2007 uitgezet onder de studentleden van de KNMG (ten tijde van de enquête waren dat er 6216). Aan alle ondervraagde studenten werd een drietal stellingen voorgelegd met betrekking tot professionele autonomie. In de inleiding van de enquête werd het begrip 'professionele autonomie' als volgt omschreven: "Professionele auto- nomie betekent voor de arts dat hij/zij zelfstandig bepaalt welke diagnostiek en behandeling voor de patiënt noodzakelijk is." De volgende stellingen werden geponeerd.

- Stelling 1: "Autonomie is een absolute voorwaarde om je werk als arts uit te kunnen voeren".

- Stelling 2: "Alleen de arts mag en kan bepalen wat de inhoud van goede zorg is". Deze stelling werd ingeleid met de vermelding dat zorgverzekeraars, de Inspectie voor de Volksgezondheid en de overheid allemaal eigen opvattingen hebben over wat kwalitatief goede zorg is.

- Stelling 3: "Het werken met protocollen is een inperking van de professionele autonomie". De inleiding van stelling 3 gaf weer dat de student geneeskunde als toekomstig arts veel zal werken met protocollen waarin behandelvoorschriften staan.

De studenten konden de stellingen beantwoorden met eens / oneens / geen mening. Daarnaast bestond de mogelijkheid commentaar te geven. Dit commentaar is meegenomen in de discussie in dit artikel.

\section{Resultaten}

Het responspercentage was $32.5 \%$, waarvan $73 \%$ vrouw en $40 \%$ coassistent. De deelname vanuit alle acht faculteiten Geneeskunde was representatief voor de verdeling van de studentenpopulatie over de faculteitssteden (zie tabel 1 en 2). 
Medisch studenten en professionele autonomie |J.A. Dekker et al.

Tabel 1. Respons per faculteit in relatie tot het totale aantal studenten geneeskunde per faculteit.

\begin{tabular}{lcccc}
\hline & \multicolumn{2}{c}{ Respondenten } & \multicolumn{2}{c}{$\begin{array}{c}\text { Studenten } \\
\text { geneeskunde }\end{array}$} \\
\hline Faculteit & $\mathrm{n}$ & $\%$ & $\mathrm{n}$ & $\%$ \\
AMC & 178 & 9 & 2174 & 13 \\
VUmc & 159 & 8 & 2172 & 13 \\
LUMC & 258 & 13 & 2022 & 12 \\
ErasmusMC & 238 & 12 & 2338 & 13 \\
UMCU & 277 & 14 & 2058 & 12 \\
UMC St. Radboud & 337 & 17 & 1969 & 12 \\
AZM & 277 & 14 & 1932 & 11 \\
UMCG & 258 & 13 & 2447 & 14 \\
Totaal & 1982 & 100 & 17112 & 100 \\
\hline
\end{tabular}

Tabel 2. Demografische kenmerken van respondenten in relatie tot het totale aantal studenten geneeskunde.

\begin{tabular}{lcccr}
\hline & \multicolumn{2}{c}{ Respondenten } & \multicolumn{2}{c}{$\begin{array}{c}\text { Studenten } \\
\text { geneeskunde }\end{array}$} \\
\hline Geslacht & $\mathrm{n}$ & $\%$ & $\mathrm{n}$ & $\%$ \\
Man & 535 & 27 & 5922 & 35 \\
Vrouw & 1447 & 73 & 11190 & 65 \\
Totaal & 1982 & 100 & 17112 & 100 \\
\hline
\end{tabular}

In totaal vindt $59 \%$ van de respondenten dat autonomie een absolute voorwaarde is om het werk als arts te kunnen uitvoeren. Mannen zijn het hiermee vaker eens dan vrouwen. Daarbij geeft in totaal 38\% van de respondenten aan dat alleen de arts mag en kan bepalen wat de inhoud van goede zorg is. Bijna een kwart (23\%) van de respondenten vindt dat protocollen een inperking van de professionele autonomie zijn; studenten in de preklinische fase zijn het hiermee vaker eens dan coassistenten. Daarnaast voelen de mannen zich ook meer beperkt door protocollen dan hun vrouwelijke collega's (zie tabel 3).

\section{Discussie}

Coassistenten hechten meer waarde aan autonomie en ervaren protocollen minder vaak als een inperking dan hun collega's die nog in de preklinische fase verkeren. Dit verschil is waarschijnlijk deels gebaseerd op ervaringen in de kliniek en deels op voortschrijdende kennis. Mannen hechten meer waarde aan autonomie en zien protocollen vaker als een inperking dan vrouwen; dit is een verschijnsel dat vaker is beschreven. ${ }^{3}$

Uit de commentaren blijkt dat studenten geneeskunde vinden dat de patiënt een belangrijke rol speelt in het beslissingsproces rondom diagnostiek en be-

Tabel 3. Meningen van studententen geneeskunde over professionele autonomie.*

\begin{tabular}{|c|c|c|c|c|c|}
\hline \multirow[b]{2}{*}{ Percentage dat het eens is met de stelling: } & \multirow[t]{2}{*}{ Totaal } & \multicolumn{2}{|c|}{ Geslacht } & \multicolumn{2}{|c|}{ Fase } \\
\hline & & Mannen & Vrouwen & Pre-klinisch & Coassistent \\
\hline $\begin{array}{l}\text { - Autonomie is een absolute voorwaarde } \\
\text { voor beroepsuitoefening }\end{array}$ & $59 \%$ & $67 \%$ & $56 \%$ & $57 \%$ & $62 \%$ \\
\hline $\begin{array}{l}\text { - Alleen arts mag/kan bepalen wat goede } \\
\text { zorg is }\end{array}$ & $38 \%$ & * & * & $36 \%$ & $42 \%$ \\
\hline $\begin{array}{l}\text { - Protocollen zijn een beperking van de } \\
\text { professionele autonomie }\end{array}$ & $23 \%$ & $30 \%$ & $21 \%$ & $25 \%$ & $21 \%$ \\
\hline
\end{tabular}

* Genoemde resultaten verschillen significant per subcategorie $\left(\mathrm{X}^{2}\right.$-toets, $\left.\alpha=0.05\right)$, behalve de met ${ }^{*}$ gemerkte cellen. 
handeling. Deze bevinding past bij het beeld dat sinds de jaren tachtig in Nederland de participatie van de patiënt bij het behandelplan is verbeterd. ${ }^{4}$ In deze in de loop der jaren ontstane verschuiving van de balans tussen autonomie van de arts en de autonomie van de patiënt kunnen de studenten zich vinden. Daarnaast zien studenten een belangrijke rol voor hun collega's weggelegd. Zij zien een taak voor andere artsen om hen te wijzen op mogelijke fouten. Inmenging van de zorgverzekeraars daarentegen is minder gewenst. Tevens zijn zij van mening dat de overheid daarnaast een sturende rol heeft, omdat zij aangeeft wat vergoedbaar is. Maar het zou de gezondheidszorg ten goede komen als artsen meer bij het landelijk beleid betrokken zouden zijn.

Het feit dat ongeveer een kwart van de respondenten protocollen wel ervaart als een inperking baart zorgen. Protocollen hebben zowel een interne als externe werking (ook derden kunnen zich op de toepassing van het protocol beroepen) en de arts mag gemotiveerd van een protocol afwijken. ${ }^{5}$ Studenten geneeskunde hebben, met name in de preklinische fase, wellicht nog onvoldoende zorginhoudelijke deskundigheid om beargumenteerd af te wijken. Dit zou de reden kunnen zijn dat zij protocollen als beperkend ervaren. Verschillende studenten geven aan dat ze niet zitten te wachten op 'kookboek'-geneeskunst: er moet altijd ruimte blijven voor eigen inbreng van de arts.

De sterke kant van deze studie is naast het feit dat de enquête door bijna tweeduizend studenten is ingevuld, ook de representativiteit van deze groep voor de studentenpopulatie. Een minder sterke kant is het gebrek aan nuance in de antwoordmogelijkheid bij de voorgelegde stellingen (eens / oneens / geen mening). De analyse van de door de studenten geplaatste opmerkingen compenseert dit gemis enigszins.

\section{Conclusie}

Uit bovenstaande resultaten is te concluderen dat studenten een vrij conservatief beeld hebben over de invulling van het begrip professionele autonomie. Een verklaring hiervoor zou gezocht kunnen worden in een beperkte kennis over de inhoud van het begrip en wat dit voor de klinische praktijk betekent. Van artsen wordt echter wel verwacht dat ze zich kunnen positioneren in hun rol als arts. Deze positionering zal gebrekkig verlopen als de kennis over de rechten en plichten en de redenen achter de plichten, niet duidelijk zijn. Het KNMG Studentenplatform vindt daarom dat studenten geneeskunde tijdens hun academische vorming al op de hoogte moeten zijn van de betekenis en consequenties van professionele autonomie en van de administratieve en juridische aspecten die daaruit voortvloeien. Uit een eerder onderzoek van het KNMG Studentenplatform blijkt dat studenten hieraan wel behoefte hebben. Dit onderzoek toont aan dat $37 \%$ van de studenten vindt dat er in de basisopleiding onvoldoende aandacht is voor juridische aspecten. Meer dan de helft van de studenten meent dat er onvoldoende aandacht is voor het gezondheidszorgstelsel en $83 \%$ van de ondervraagde studenten vindt dat de administratieve aspecten van hun vak te weinig worden belicht terwijl ze tijdens de studie aangeven deze aspecten wél belangrijk te vinden. ${ }^{6}$

Vanwege de bijzondere verantwoordelijkheid van de arts (professionele autonomie), de kennis die daarvoor nodig is en de behoefte van studenten aan juridische, administratieve en gezondheidsrechtelijke aspecten, acht het KNMG Studentenplatform het wenselijk om het vak gezondheidsrecht verplicht te stellen in het curriculum. Dit stelt studenten, en de artsen die zij later zullen worden, in staat zich een meer realistisch beeld te vormen van professionele autonomie. 
Medisch studenten en professionele autonomie $\mid$ J.A. Dekker et al.

\section{Literatuur}

1. Jeurissen R, Dartel H van. Professionaliteit in de zorg - naar nieuwe definiëringen van oude rollen. TGE 2006;16(2):61-65. [Professionalism in health care - towards a new definition of old roles. TGE 2006;16(2):61-65].

2. KNMG Manifest Medische professionaliteit. Utrecht: KNMG; 2007. [The Royal Dutch Medical Association's manifest on medical professionalism. Utrecht: KNMG; 2007].

3. Kruijthof K. Doctors' Orders: Specialists' Day to Day Work and their jurisdictional Claims in Dutch Hospitals. Nieuwegein: Badoux; 2005.

4. Brink-Muinen A van den, Dulmen SM van, Haes HC de, Visser AP, Schellevis FG, Bensing JM. Has patients' involvement in the decision-making process changed over time? Health Expect 2006 Dec;9(4):333-42.

5. HR 2 maart 2001, NJ 2001, 649. [Supreme Court 2 mars 2001, Journal of Dutch Jurisprudence 2001, 649].

6. Oosterhout WPJ van, Dekker JA. Metamedica in de basisopleiding geneeskunde. Tijdschrift voor Medisch Onderwijs 2007;26(3):128-34. [Metamedical topics for undergraduate medical education. Dutch Journal of Medical Education 2007;26(3):128-34].

\section{De auteurs:}

Mw. J.A. Dekker LLB is vierdejaars student geneeskunde, ErasmusMC en masterstudent rechtstheorie, rechtseconomie en gezondheidsrecht, Erasmus Universiteit Rotterdam.

Drs. W.P.J. van Oosterhout is arts-onderzoeker Neurologie, Leids Universitair Medisch Centrum.

Mw. M.M.C. Lambregts is coassistent, Universitair Medisch Centrum Groningen.

Correspondentieadres:

Mw J.A. Dekker, Schildmos 6, 3994 LS Houten. Tel: 0614738800; e-mail: Judith_Anna_Dekker@hotmail.com

Belangenconflict: geen gemeld.

Financiële ondersteuning: geen gemeld.

\section{Summary}

Introduction: In view of the specific nature of the medical profession, the Dutch legislature leaves it to the medical profession to determine its own standards of professionalism. This responsibility is also referred to as professional autonomy.

Method: The Student Platform of the Royal Dutch Medical Association (KNMG) commissioned a questionnaire survey among more than $6.000 \mathrm{KNMG}$ student members to investigate medical students' interpretations of professional autonomy, the value they place on it and their views on protocols in medicine.

Results: The response was 32.5\%. Over 59\% of the respondents viewed professional autonomy as a prerequisite for doctors to be able to function as a medical professional. According to $38 \%$ of the respondents, doctors are the only ones who are qualified to define what constitutes good health care. According to $23 \%$ of the respondents, protocols restrict doctors' professional autonomy.

Discussion and conclusion: Considering doctors' unique responsibilities (professional autonomy), the knowledge required to fulfil these responsibilities and students' need for education in legal, administrative and health law aspects of medicine, KNMG Student Platform proposes mandatory education in health law to be integrated into the Dutch undergraduate medical curriculum. This will provide students, as the doctors of the future, a more realistic picture of professional autonomy. (Dekker JA, Oosterhout WPJ van, Lambregts MMC. Medical students'views on professional autonomy. Dutch Journal of Medical Education 2008;27(4):166-170.) 